\title{
A Non-Gaussian Pricing Model for Structured Products
}

\section{Denis V. Zuev,}

$\mathrm{PhD}$ in Economics, Section Head at the Department of Finance, Moscow Exchange (MOEX): 13, Bolshoy Kislovsky lane, Moscow, Russian Federation, 125009

E-mail: denconvert@mail.ru

\begin{abstract}
The paper aims to reconstruct the empirical premia of the structured products with two underlying assets. We apply various models that differ in probability distributions of the underlying price processes.

Pricing techniques, currently worldwide accepted, are based on the Black-Scholes model modifications with Gaussian distributions. Conventionally a correlation between underlying price processes is not considered. In order to achieve the overall objective the paper suggests a pricing model of structured products. The model considers a non-Gaussian realistic market framework for pricing the underlying assets and takes into account their correlation.

The theoretical and methodological basis of our research is quantitative finance, evolutionary equations, dynamical systems and field theory.

The paper presents an example of pricing a range of structured products.

We find that the approach to the theoretical premium valuation of the complex financial instrument is interrelated bijectively with statistical properties of the underlying assets. In particular, the paper presents the effectiveness of our model with regard to the structured derivatives with the correlated assets that obey non-Gaussian distributions. The fair value of the structured product evaluated using our model outperforms estimates obtained by means of other methods as it allows lower fair price of the derivatives.

The results of our research may be beneficial to academics, market participants including market analysts, risk-managers and developers of financial products.

We have concluded that market participants carry extra costs due to the simple models of the structured products' fair value pricing they apply.

The proposed model looks especially promising within the context of the complex derivatives market which growth has been accompanied by low liquidity and high premia, in the absence of a unique framework for pricing the structured products that would be consistent with financial market practice.
\end{abstract}

Keywords: fair value, non-Gaussian joint probability density function with skew, payout function, structured derivatives market, structured product, structured products pricing methodology.

JEL: G12, G13. 


\section{State of the art}

During the last two decades the world has witnessed strong growth in structured derivatives turnover and expansion of product range. These flexible instruments offer a variety of investment solutions for different types of investors to enhance performance or reduce risk. Investment banks and companies issue structured products with varying terms, payouts and risk profiles tracking the performance of underlying assets which can be equities, indexes, commodities, currencies or baskets. Structured products offer exposure to a diverse range of markets and underlying assets.

Nevertheless, liquidity of the structured derivatives market is miniscule in comparison with standardized instruments boards (futures, options and swaps markets). The main problem is the absence of a unique framework for pricing the structured products that would be consistent with financial market practice - a non-Gaussian stochastic behavior of the underlying assets premia [Voit, 2005; Bollerslev, Todorov, 2011; Bollerslev, Todorov, 2014]. Pricing techniques, currently worldwide accepted, are based on Gaussian distributions. Conventionally a correlation between underlying price processes is not considered. Due to the two fiascos of pricing models (lack of a non-Gaussian framework and disregard of assets correlation) fair values in the structured derivatives market are hard to estimate. Professional participants and financial institutions perceive the absence of fair value as an extra uncertainty. Hence follows that structured products premia contain an excess value as a market price of this extra risk. Since the market price of risk is systematically overestimated, an overall level of structured products premia is high. This empirical fact explains low liquidity of the complex derivatives market.

The paper aims to suggest a solution to the fair-value-absence problem that cripples the structured products market. We propose a pricing model based on bivariate non-Gaussian skewed joint probability distributions of underlying assets price processes. The proposed approach is invariant to the structured product type. An implementation of the model shall provide a fair pricing, a decrease in overall level of structured products premia and an impetus to liquidity. Investors that merely regard structured products as a potential investment solution shall get a more welcoming gate to the complex derivatives market.

A structured product is a complex financial instrument with two or more underlying assets. Therefore, the model shall be based on multivariate probability distributions. As part of the model construction, we develop a mathematical tool for pricing a theoretical value of structured products with two underlying assets. It is a challenging research problem.

In the empirical part of the paper, we present the structured products that replicate a range of standardized derivatives based on univariate price processes. The components of proposed financial instruments are derivatives. It provides an opportunity to compare a theoretical premium of the structured product with a sum of prices of replicated derivatives.

\section{The model}

Suppose the structured product has two underlying assets. Then the value F, considered as a function of current time $t$, states $\mathrm{x}$ and $\mathrm{y}$, solves the Kolmogorov backward equation (the Dynkin infinitesimal operator) [Baz, Chacko, 2004; Björk, 2009]:

$$
\begin{aligned}
& -\frac{d F(x, y, t)}{d t}=\frac{1}{2} \sigma_{1}^{2}(x, y) \times \frac{d^{2} F(x, y, t)}{d x^{2}}+\frac{1}{2} \sigma_{2}^{2}(x, y) \times \frac{d^{2} F(x, y, t)}{d y^{2}}+\sigma_{1}(x, y) \times \sigma_{2}(x, y) \times \rho_{12} \times \\
& \times \frac{d}{d y}\left(\frac{d F(x, y, t)}{d x}\right)+\mu_{1}(x, y) \times \frac{d F(x, y, t)}{d x}+\mu_{2}(x, y) \times \frac{d F(x, y, t)}{d y}-r \times F(x, y, t),
\end{aligned}
$$

where $F(x, y, t)$ - unknown function of two financial variables $\mathrm{x}$ and $\mathrm{y}$ that characterize the dynamics of underlying assets market premia (i.e. F determines a time evolution of the structured product's fair value); $\mu_{1}(x, y)$ and $\mu_{2}(x, y)$ -

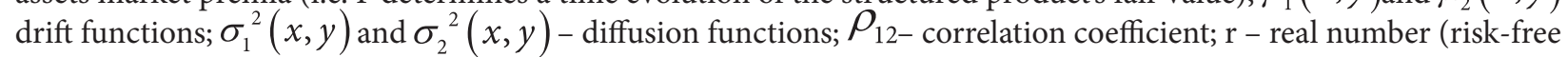
interest rate)

with the terminal payout condition at expiry:

$$
F(x, y, T)=\Phi(x, y)
$$

where $\Phi(x, y)$ - payout function at expiry $\mathrm{T}$ of the structured product.

In accordance with Feynman-Kac formula [Baz, Chacko, 2004; Björk, 2009] the general solution F of (1) with the terminal payout condition (2) may be written in the form:

$\mathrm{F}(\mathrm{x}, \mathrm{y}, \mathrm{t})=\sum_{\mathrm{n}=0}^{+\infty}\left(\gamma_{n}(x, y) \times e^{-\lambda_{n}(T-t)} \times \int_{\mathrm{K}_{2}^{\mathrm{y}}}^{\mathrm{b}} \int_{1}^{\mathrm{K}} \gamma_{n}(x, y) \times w(x, y) \times \Phi(x, y) d x d y\right)$, 
where $\gamma_{n}(x, y)$ - eigenfunctions; $\lambda_{n}$ - corresponding eigenvalues; $\mathrm{n}$ - serial number of the eigenfunction $\gamma(x, y)$ and the corresponding eigenvalue $\lambda$; T - expiry; $\mathrm{t}$ - time from entry until expiry T; $w(x, y)$ - weighting function; $\Phi(x, y)$ - payout function; $K_{1}^{x}$ и $K_{2}^{y}$ - separated strikes; a - minimum value of x with regard to the contract period and given prior period; $b$ - maximum value of $y$ with regard to the contract period and given prior period.

Let's take a closer look at each component of the formula (3).

1) Weighting function $w(x, y)$. The nature of underlying price processes diffusion is indeterminate. It is impossible to identify a pair of uniquely specified diffusion functions $\sigma_{1}^{2}(x, y)$ and $\sigma_{2}^{2}(x, y)$. It seems more convenient for the market purposes to define an approximation of time evolution of the probability density function of the structured product's underlying price processes in terms of the Liouville first-order partial differential equation in I. Prigogine's and G. Nicolis' specification (hereinafter referred to as "the Prigogine equation") [Nicolis, Prigogine, 1989]:

$\frac{d \rho(x, y, t)}{d t}=-\frac{d \rho(x, y, t)}{d x} \times E(x, y)-\rho(x, y, t) \times \frac{d E(x, y)}{d x}-\frac{d \rho(x, y, t)}{d y} \times$

$\times G(x, y)-\rho(x, y, t) \times \frac{d G(x, y)}{d y}$,

where $\rho(x, y, t)$ - unknown time-evolving bivariate non-Gaussian skewed joint probability density function of two random variables $\mathrm{x}$ and $\mathrm{y}$ that characterize the dynamics of underlying assets market premia; $\mathrm{E}(\mathrm{x}, \mathrm{y})$ and $\mathrm{G}(\mathrm{x}, \mathrm{y})-\mathrm{right}$ parts of the equations of motion (dynamical system).

In other words, we define a time evolution by applying a dynamical system for the logarithms of empirical average prices of financial assets. The solution of the Prigogine equation (4) after separation of variables is a weighting function w(x,y) that stands for bivariate non-Gaussian skewed joint probability density function of two underlying price processes:

$\rho(x, y, t)=w(x, y) \times \check{T}(t)$

$\mathrm{E}(\mathrm{x}, \mathrm{y}) \cdot \frac{\mathrm{dw}(\mathrm{x}, \mathrm{y})}{\mathrm{dx}}+\mathrm{G}(\mathrm{x}, \mathrm{y}) \cdot \frac{\mathrm{dw}(\mathrm{x}, \mathrm{y})}{\mathrm{dy}}+\mathrm{w}(\mathrm{x}, \mathrm{y}) \cdot\left(\frac{\mathrm{dE}(\mathrm{x}, \mathrm{y})}{\mathrm{dx}}+\frac{\mathrm{dG}(\mathrm{x}, \mathrm{y})}{\mathrm{dy}}-\alpha\right)=0$,

$\check{T}(t)=A \cdot e^{-\alpha \cdot t}$

where $\alpha$ - eigenvalue that corresponds to a weighting function $\mathrm{w}(\mathrm{x}, \mathrm{y}) ; \mathrm{A}-\operatorname{arbitrary}$ constant.

It raises the fundamental question: why are we allowed to use the solution of the Prigogine equation (5) for the view of a time-evolving fair value of the structured product (3)?

The Prigogine equation (5) is a field for the Dynkin equation (1) if a certain function $\psi(w(x, y), x, y)$ satisfies the bivariate Hamilton-Jacobi equation for the Dynkin equation. Thus, specifying a field of the Dynkin equation in some region $\mathrm{V}$ defines an n-parameter family of solutions of the Dynkin equation, such that one and only one curve from the family passes through each point of V. Given that the Prigogine equation is a field for the Dynkin equation (with a certain function $\psi(\mathrm{w}(\mathrm{x}, \mathrm{y}), \mathrm{x}, \mathrm{y})$ - solution of the Hamilton-Jacobi equation), we are allowed to conclude that the solution of the Dynkin equation (1) is identical with the formula (3). Last-mentioned (3) is based on the probability density function $\mathrm{w}(\mathrm{x}, \mathrm{y})$ as a solution of the Prigogine equation (5).

The equation (5) contains, in its left part, the nonlinear right parts of the equations of motion (dynamical system) $\mathrm{E}(\mathrm{x}, \mathrm{y})$ and $\mathrm{G}(\mathrm{x}, \mathrm{y})$. These functions describe a time evolution of financial variables underlain the structured product that are distributed not in accordance to the Gauss's law. In our research we have developed an approach to setting the dynamical system. The main point of the approach is following.

A price process after the trend elimination is irregularly cyclical. At a qualitative level it is closer to the OrnsteinUhlenbeck processes that consider a mean reversion. The simplest formalism applied to describing real natural cyclical processes with mean reversion (e.g. a Belousov-Zhabotinsky chemical reaction) is a typical non-linearity that provides a Poincaré-Andronov-Hopf bifurcation [Marsden, McCracken, 1976]. This bifurcation is related to the appearance (or disappearance) of limit cycle from a multiple focus of finite-dimensional dynamical system. A minimal model in which a Poincaré-Andronov-Hopf bifurcation is conceivable shall consist of two equations. Applying the methods of normal forms theory in typical case leads the equations to the form [Guckenheimer, Holmes, 2002; Marsden, McCracken, 1976]: 


$$
\begin{aligned}
& \frac{d x(t)}{d t}=E(x, y)=\left(d \cdot q+u \cdot\left(x^{2}+y^{2}\right)\right) \cdot x-\left(m+c \cdot q+v \cdot\left(x^{2}+y^{2}\right)\right) \cdot y \\
& \frac{d y(t)}{d t}=G(x, y)=\left(m+c \cdot q+v \cdot\left(x^{2}+y^{2}\right)\right) \cdot x+\left(d \cdot q+u \cdot\left(x^{2}+y^{2}\right)\right) \cdot y
\end{aligned}
$$

where $c, d, m, q, u, v$ - scalar parameters (see below).

In the literature on dynamical systems theory [Guckenheimer, Holmes, 2002; Marsden, McCracken, 1976] it is the most typical non-linearity among all candidate for right parts of the equations of motion in the sense that it fits a very broad class of objects. Thus, we apply it to the description of price processes that are qualitatively similar to some processes well-studied in natural sciences.

The parameters of dynamical system (6) c, d, m, q, u, v are numerically defined using market prices of the underlying assets that form a structured product (while financial variables $\mathrm{x}$ and $\mathrm{y}$ in (6) characterize the dynamics of underlying assets market premia). For this purpose, we use the method of projection on the center manifold [Mathews, Walker, 1970], similarity transformation, and minimization of the mean squared error [Duda, Hart, 1973] (numerical revaluation on a finite number of points is performed repeatedly with new available market information).

By setting the right parts of the equations of motion as in (6), the Prigogine nonhomogeneous first-order partial differential equation (5) with two nontrivially correlated variables is solved with regard to a bivariate non-Gaussian skewed joint probability density function $\mathrm{w}(\mathrm{x}, \mathrm{y})$. It is impossible to find an analytical (closed-form) solution of the equation (5) with given right parts of the equations of motion (6). Thus, the initial differential equation (5), which is a Sturm-Liouville problem, is solved in its equivalent form of a problem in the calculus of variations. The equation (5) with a given natural boundary conditions (Feller's boundary classification [Feller, 1968; Feller, 2015]) is solved numerically by means of the direct (Ritz) method.

In what follows, basis functions $\gamma(\mathrm{x}, \mathrm{y})$ shall be generated using power moments of the probability density function, $\mathrm{w}(\mathrm{x}, \mathrm{y})$, obtained as a solution to the Prigogine equation (5).

2) Basis functions (eigenfunctions) $\gamma(x, y)$. Basis is responsible for a time evolution of price process. The projection on a chosen basis is a solution of the initial differential equation.

We form basis functions (a set of orthonormal polynomials of two variables, i.e. basis) $\gamma(\mathrm{x}, \mathrm{y})$ using a modified (fitted to multivariable functions) operator that is based on determinants of Hankel matrices (the Hamburger's approach) of power moments $\mathrm{M}(\mathrm{x}, \mathrm{y}, \mathrm{n}, \mathrm{k})$ of a weighting function (a probability density function) $\mathrm{w}(\mathrm{x}, \mathrm{y})$ :

$\mathrm{M}(\mathrm{x}, \mathrm{y}, \mathrm{n}, \mathrm{k})=\iint_{0}^{\mathrm{r}} \mathrm{x}^{\mathrm{n}-\mathrm{k}} \cdot \mathrm{y}^{\mathrm{k}} \cdot \mathrm{w}(\mathrm{x}, \mathrm{y}) \mathrm{dxdy}$,

where $\Gamma$ - an upper limit of integration domain that corresponds to an upper limit of a weighting function domain (i.e. an upper limit of integration domain where a volume under the surface of a weighting function equals to one).

A formula for orthonormal polynomials is written in the form:

$$
\gamma_{\mathrm{nk}}(\mathrm{x}, \mathrm{y})=\frac{1}{\sqrt{\Delta_{\mathrm{n}, \mathrm{k}-1} \cdot \Delta_{\mathrm{nk}}}} \cdot \mathrm{P}_{\mathrm{nk}}(\mathrm{x}, \mathrm{y})
$$

(if $\mathrm{k}=0$ we have $\Delta_{\mathrm{n}-1, \mathrm{n}-1} \cdot \Delta_{\mathrm{n} 0}$ under the radical sign), where (the values of power moments from the formula (7) are denoted there as $\mathrm{M})$ :

$$
\Delta_{\text {nk }}=\left|\begin{array}{ccccc}
M_{00} & M_{10} & M_{11} & \ldots & M_{n k} \\
M_{10} & M_{20} & M_{21} & \ldots & M_{n+1, k} \\
M_{11} & M_{21} & M_{22} & \ldots & M_{n+1, k+1} \\
\ldots & \ldots & \ldots & \ldots & \ldots \\
M_{n k} & M_{n+1, k} & M_{n+1, k+1} & \ldots & M_{2 n, 2 k}
\end{array}\right|, \ldots
$$




$$
\mathrm{P}_{\mathrm{nk}}(x, y)=\left|\begin{array}{ccccc}
M_{00} & M_{10} & \ldots & M_{n, k-1} & M_{n k} \\
M_{10} & M_{20} & \ldots & M_{n+1, k-1} & M_{n+1, k} \\
\ldots & \ldots & \ldots & \ldots & \ldots \\
M_{n, k-1} & M_{n+1, k-1} & \ldots & M_{2 n, 2(k-1)} & M_{2 n, 2 k-1} \\
1 & x & \ldots & x^{n-k+1} y^{k-1} & x^{n-k} y^{k}
\end{array}\right| .
$$

Each basis function has a power $n$ and contains a unique number of monomials of the form $\left\{x^{n}, x^{n-1} y, \ldots, x y^{n-1}, y^{n}\right\}$. Therefore, the symmetry is broken for the whole set of polynomials. It means that in the subsequent expansion of the payout function (3) we escape "a trap", i.e. there is no longer need for us to replace the original payout with replication. The obtained set of orthonormal polynomials of two variables $\gamma(\mathrm{x}, \mathrm{y})$ is a basis of the linear space that provides a time evolution of the structured product's fair value.

The basis is applied to forming a degenerate kernel for obtaining a spectrum of eigenvalues $\lambda$ that are responsible for velocity and sign of increment of a fair value of the structured product (3).

3) Eigenvalues $\lambda$. The expression (3) for a time-evolving fair value of the complex financial instrument contains eigenvalues $\lambda$ that correspond to eigenfunctions $\gamma(\mathrm{x}, \mathrm{y})$. Recall the way the spectrum has been obtained.

We start with a basis constructed on power moments of the density function that solves the Prigogine equation. Thus, we escape cumbersome calculation of eigenvalues otherwise unavoidable.

We then set up a degenerate kernel and represent it in a matrix form. The entries of the matrix are double integrals of pairwise products of the basis functions $\gamma(\mathrm{x}, \mathrm{y})$ that originate from Hankel determinants following the Hamburger method, as shown earlier:

$$
\lambda_{\mathrm{i}}=\iint_{V}\left(\gamma_{\mathrm{i}}(\mathrm{x}, \mathrm{y}) \cdot \gamma_{\mathrm{j}}(\mathrm{x}, \mathrm{y})\right) d x d y \text {. }
$$

The eigenvalues of that matrix are taken as eigenvalues $\lambda$ from the formula (3). Thus, we obtain a spectrum as the eigenvalues of the matrix which entries are pairwise products of the basis functions $\gamma(\mathrm{x}, \mathrm{y})$, i.e. double integrals.

This approach provides a monotonicity of spectrum of eigenvalues fitting to the min-max principle of R. Courant (the Courant theorem).

4) Payout function $\Phi(x, y)$. Alongside with a probability density function $\mathrm{w}(\mathrm{x}, \mathrm{y})$, basis functions $\gamma(\mathrm{x}, \mathrm{y})$ and eigenvalues $\lambda$ the expression (3) for a time-evolving fair value $F(x, y, t)$ of the structured product contains weighting coefficients $A_{n}$. They are coefficients of expansion of the payout function $\Phi(\mathrm{x}, \mathrm{y})$ by the basis in the corresponding integration domain:

$$
A_{n}=\int_{K_{2}^{y}}^{b} \int_{a}^{K_{1}^{x}} \gamma_{n}(x, y) \cdot w(x, y) \cdot \Phi(x, y) d x d y,
$$

where $K_{1}^{x}, K_{2}^{y}$, a, b-defined above, see (3).

The payout function of structured products with two underlying stochastic price processes determines the financial result of a deal at expiry. It is a function of two financial variables $\mathrm{x}$ and $\mathrm{y}$. E.g.:

$\Phi(x, y)=\left\{\begin{array}{c}(y-x)-K, \text { if }(y-x)>K \\ 0, \text { if }(y-x) \leq K,\end{array}\right.$

where $\mathrm{K}$ - a strike price of the structured product.

The integration domain in (12) is, in turn, determined by a payoff profile of the contract. Thus, the entire integration domain or either lower or upper limits of integration of the double integral in (12) may be variable.

It should be emphasized here that the weighting coefficients $A_{n}(12)$ in the formula (3) depend on the specification of payout function $\Phi(\mathrm{x}, \mathrm{y})$ and payoff profile of the structured product. In other words, a choice of a payout function and setting the accessory (terminal or terminal and boundary) conditions of the problem influence the weighting coefficients $\mathrm{A}_{\mathrm{n}}$ and therefore predetermine fair value of the structured product. 
Given the probability density function $\mathrm{w}(\mathrm{x}, \mathrm{y})$, basis functions $\gamma(\mathrm{x}, \mathrm{y})$, eigenvalues $\lambda$, weighting coefficients $\mathrm{A}_{\mathrm{n}}$ and the integration domain in the expression (3) we obtain the sought-after function $F(x, y, t)$ of two financial variables $x$ and $y$; the latter describe the dynamics of the underlying assets' market premia. $\mathrm{F}(\mathrm{x}, \mathrm{y}, \mathrm{t})$ determines time evolution of the structured product's fair value.

Inserting the values of financial variables $\mathrm{x}$ and $\mathrm{y}$ (i.e. market prices of the underlying assets) at moment $\mathrm{t}$ into the function $\mathrm{F}(\mathrm{x}, \mathrm{y}, \mathrm{t})$ we get a fair value of the complex financial instrument at time $\mathrm{t}$.

Two essential remarks are required here.

Firstly, the real-life financial markets we consider are marked by imperfect (incomplete) efficiency. It means that market participants are challenged by a time delay in data handling. Consequently there is a delayed response to incoming information.

The prices of complex financial instruments depend on the underlying assets premia. Setting the latter precedes setting the former. It is a natural prerequisite for prices forecasting of the structured products by means of the proposed model. Inserting the market prices of the underlying assets at time $t$ into the function $F(x, y, t)$, we get a premium of the structured derivative at a point in time with a small increment, $t+\varepsilon$.

Secondly, we obtain a probability density function $\mathrm{w}(\mathrm{x}, \mathrm{y})$, basis functions $\gamma(\mathrm{x}, \mathrm{y})$ and eigenvalues $\lambda$ exogenously as regards the Dynkin equation (1). Identification of the relationship linking the Dynkin and the Prigogine equations is a valuable output of the research we have embarked on.

\section{Empirical analysis and results}

The models of a fair value ${ }^{1}$ pricing of financial instruments make it possible to reconstruct their empirical premia. A mean squared deviation of the theoretical price from its empirical observation (i.e. a precision of estimate) stands for consistency measure of the reconstruction. The efficiency of the model is determined by comparing mean squared deviations of premia from the empirical prices. The premia are obtained by applying various models that differ in probability distributions of the underlying price processes. The higher precision of a fair value estimate and the higher statistical reliability of all solution parameters with the Lyapunov stability are, the more effective the model is. But with regard to the structured products, we face the following institutional problem.

The complex financial instruments are bargained in an over-the-counter (OTC) market. Investment banks and management companies do not disclose their pricing. Hence, current and historical prices of the structured products are not available for the providers of financial information, in particular Bloomberg agency [The Bloomberg Professional Service (Bloomberg Terminal)].

Nevertheless, we have a range of empirical net prices ${ }^{2}$ of the concluded deals with the structured product of the largest Swiss financial conglomerate. The product is based on two price processes. This data gives us an opportunity to identify the convergence of theoretical prices ${ }^{3}$ of the existing complex financial instrument to the empirical premia. We propose the following inductive logic for projection of the results of these particular deals' pricing on the structured derivatives market in general. It is aimed to solve two tasks - estimate an efficiency of the proposed model and define the key results of our research.

First we estimate the standardized exchange-traded instruments by applying three models that differ in probability distributions of the underlying price processes (Black-Scholes option pricing model [Black, Scholes, 1973]; non-Gaussian option pricing model with skew [Borland, 2002a]; an application of the proposed model for univariate case). The pricing of the liquid standardized instruments (that are based on univariate stochastic process) is close to a fair ${ }^{4}$. Thereby an analytical estimation of the theoretical premia (e.g. option premium) is the empirics' reconstruction. A consistency measure of the reconstruction is a mean squared deviation of the theoretical price from its empirical observation. Make sure that the proposed model for the bivariate case performs advantageous results ${ }^{5}$ in the univariate case where the empirical observation is a benchmark. Prove a non-Gaussian stochastic behavior of the underlying assets pricing ${ }^{6}$.

Then we estimate the existing structured product based on two price processes by applying several approaches (BlackScholes model modifications for the bivariate case [Mattoo, 1996; Wystup, 2006; Cheuk, Vorst, 1996; Davydov, Linetsky, 2002; Douady, 1998; Fu, Madan, Wang, 1997; Geman, Yor, 1993, 1996; Hui, 1997; Lasserre, Prieto-Rumeau, Zervos, 2006;

\footnotetext{
1 The terms "fair value" and "theoretical premium/price/value" are used interchangeably here.

${ }^{2}$ Bank margin is eliminated.

3 The prices are obtained by applying various models.

${ }^{4}$ In contrast to the complex products that are traded in the OTC market.

${ }^{5}$ The highest precision of estimate and the highest statistical reliability of all solution parameters with the Lyapunov stability.

${ }^{6}$ VIX options [The Chicago Board Options Exchange (CBOE)] are involved in testing the model; VIX index [S\&P Dow Jones Indices; The Chicago Board Options Exchange (CBOE)] is one of the underlying assets of the proposed product range of the complex financial instruments.
} 
Linetsky, 2004; Pelsser, 2000; Risk magazine (Incisive Media); Structured Retail Products]; the proposed model). The estimation of the theoretical premium of the complex financial instrument is the reconstruction of the bank pricing techniques $^{7}$, not the empirics in canonical sense (i.e. when we obtain the fair values of the liquid standardized exchange-traded instruments). An empirical data on the deals with the structured products is a result of the specific bank pricing models application. Comparing the theoretical values ${ }^{8}$ with the empirics, we shall speak not about a precision rate of the theoretical estimates with regard to the market premia but about a sign of the expected value of difference between them. With the aim of this comparing it is important to note that the empirical data has to be eliminated from the bank margin (i.e. the fees that contain, in particular, the client default risk). Comparing the theoretical prices of the existing complex financial instruments with the real market deals' prices provides us an opportunity to answer the question about the expensiveness of the structured products.

Finally we estimate the proposed product range of the complex financial instruments based on two price processes by applying several approaches (Black-Scholes model modifications for the bivariate case [Mattoo, 1996; Wystup, 2006; Cheuk, Vorst, 1996; Davydov, Linetsky, 2002; Douady, 1998; Fu, Madan, Wang, 1997; Geman, Yor, 1993, 1996; Hui, 1997; Lasserre, Prieto-Rumeau, Zervos, 2006; Linetsky, 2004; Pelsser, 2000; Risk magazine (Incisive Media); Structured Retail Products]; the proposed model). These instruments are not exchange-traded. We suppose that the underlying assets' (that form a structured product) pricing is almost fair. Market participants have identical estimates of the theoretical values of the derivatives based on univariate price processes. We also assume that the upper limit of a set of the complex product's estimates is close to a sum of empirical premia of the components of a scheme related to the product. The given model of product's fair value pricing influences the difference between the theoretical price and a sum of empirical premia. The results of estimates are compared with a sum of empirical premia of the underlying assets, i.e. the components of an investment strategy related to the given complex financial instrument. This approach for the empirical testing is applicable to all types of structured products in miniscule liquidity and in the absence of a fair pricing.

The proposed product range satisfies a financial market requirement of the participants for the bundle instrument that combines several multipartite deals. As shown below, the proposed complex financial instruments are the lower cost analogues of the existing structured products. They shall provide an impetus to liquidity of a range of instruments in the financial market. Moreover, the structured products development is essential for the empirical testing of the proposed model within the context of the absence of current and historical prices data of the existing complex financial instruments.

Let's turn to the inductive logic implementation.

Table 1 presents the results of theoretical premia estimation of the liquid six-month European-style call and put VIX options traded in 2010-2015 and the first half of 2016 by applying:

- Black-Scholes option pricing model based on Gaussian distribution [Black, Scholes, 1973];

- non-Gaussian option pricing model with skew based on Tsallis distributions [Borland, 2002b];

- an application of the proposed model for univariate case.

Table 1. The results of VIX options estimates (over a period of 2010-2015 and the first half of 2016)

\begin{tabular}{|c|c|c|}
\hline No & Model & $\begin{array}{l}\text { Mean squared deviation of the theoretical } \\
\text { options premia from their empirical } \\
\text { observations }\end{array}$ \\
\hline 1 & Black-Scholes model & 1.27 \\
\hline 2 & $\begin{array}{l}\text { Non-Gaussian option pricing model with skew based on } \\
\text { Tsallis distribution }\end{array}$ & 0.65 \\
\hline 3 & An application of the proposed model for univariate case & 0.27 \\
\hline
\end{tabular}

Sources: author's development; [The Bloomberg Professional Service (Bloomberg Terminal); The Chicago Board Options Exchange (CBOE); U.S. Department of the Treasury (Daily Treasury Yield Curve Rates); Yahoo! Finance] - empirical data.

\footnotetext{
${ }^{7}$ Each bank uses its own unique pricing methods, the exchange quotations are absent.

${ }^{8}$ The values are obtained by applying various models.
} 
Having considered the results of estimates of the standardized exchange-traded instruments (options) based on univariate stochastic process, we are ready to summarize our findings as follows:

- the proposed new non-Gaussian approach for the theoretical premium valuation of the structured products provides

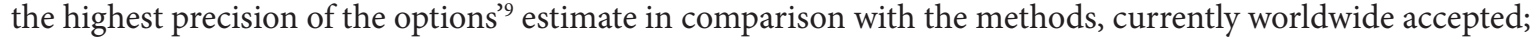

- the proposed approach and the non-Gaussian model with skew (based on Tsallis distribution) provide the higher precision of the options fair values' estimate in comparison with the Black-Scholes model. This empirical fact proves a non-Gaussian stochastic behavior of the underlying assets pricing.

Let's estimate now the theoretical premia of the existing structured product - Dual Digital Option with two underlying assets (EUR/AUD and EUR/GBP currency pairs). Table 2 demonstrates the results of estimation one of the Dual Digital Options involved in testing the model.

Table 2. The results of Dual Digital call Option estimates (at the entry day 18/03/2015)

\begin{tabular}{|c|c|c|c|c|c|c|c|}
\hline \multirow[t]{2}{*}{ No } & \multirow[t]{2}{*}{$\begin{array}{c}\text { Estimation method } \backslash \\
\text { Model }\end{array}$} & \multicolumn{3}{|c|}{$\begin{array}{l}\text { Black model modification } \\
\text { based on Gaussian distribution }\end{array}$} & \multicolumn{3}{|c|}{$\begin{array}{l}\text { Proposed model based on } \\
\text { non-Gaussian distribution }\end{array}$} \\
\hline & & F & $\Delta$ & k & F & $\Delta$ & k \\
\hline \multicolumn{8}{|c|}{ Empirical price (bank margin is eliminated): $10.42 \%$} \\
\hline 1 & $\begin{array}{l}\text { Product estimation as a sum of theoreti- } \\
\text { cal prices of replicated derivatives }\end{array}$ & $10.54 \%$ & $-0.12 \%$ & 0.99 & $9.43 \%$ & $0.99 \%$ & 1.10 \\
\hline 2 & $\begin{array}{l}\text { Product estimation by applying multi- } \\
\text { plication of two univariate distributions }\end{array}$ & $10.45 \%$ & $-0.03 \%$ & 1.00 & $9.35 \%$ & $1.07 \%$ & 1.11 \\
\hline 3 & $\begin{array}{l}\text { Product estimation by applying a bivari- } \\
\text { ate distribution }\end{array}$ & $10.43 \%$ & $-0.01 \%$ & 1.00 & $8.47 \%$ & $1.95 \%$ & 1.23 \\
\hline
\end{tabular}

where F - theoretical Dual Digital call option premium (\% of Notional principal amount); $\Delta$ - difference between empirical and theoretical premia; $\mathrm{k}$ - ratio of empirical premium to theoretical

Sources: author's development; [OANDA (exchange rates archive); The Bloomberg Professional Service (Bloomberg Terminal); U.S. Department of the Treasury (Daily Treasury Yield Curve Rates)], empirical data of a Swiss bank.

Having considered the results of estimates of the existing structured products based on two price processes, we are ready to summarize our findings as follows:

- a set of theoretical premia of the complex derivatives that are obtained by applying Black-Scholes model modifications is close to the concluded deals' prices with a bank margin eliminated. This fact evidences that market participants apply the approaches based on Gaussian distribution for the structured products valuation. Meanwhile all three estimation methods within the framework of the proposed model based on non-Gaussian distributions lead to the lower theoretical premia as compared to the empirics and Black-Scholes model modifications;

- the theoretical price of the existing structured product that is obtained by applying the bivariate distributions in each model (Black modification and the proposed model) is lower than a sum of theoretical prices of its components (replicated derivatives). This implies that the bundle instrument development that combines two deals with the correlated assets reduces an overall derivatives price level. Thus, we can define a sum of theoretical premia of the components of the structured product as the upper limit of a set of its estimates.

We draw an inductive inference that is applicable to estimation of the financial instruments without exchange quotation: the upper limit of a set of the complex product's theoretical estimates is close to a sum of empirical premia of the components of a scheme related to the product. The given method of structured product's fair value pricing influences tangibly the difference between the theoretical price and a sum of empirical premia, i.e. the price of the underlying assets correlation. Let's verify the inference by the example of the proposed range of the structured products.

One essential remark is required here.

Choosing the underlying assets we follow a general principle: the structured product has to be characterized by a managed risk-return ratio. Otherwise the product shall translate a destructive force that would be manifested in a risk infusion and expansion in the financial market. Formally, the supervision is provided by a nonlinear correlation between stochastic processes that characterize the dynamics of underlying assets market premia of the developed structured product.

9 These options are components of the developed range of the complex financial instruments. 
The dependence between stochastic processes can be defined in terms of information entropy. A Hellinger-MatusitaBhattacharya distance measure S [Granger, Maasoumi, Racine, 2004] should be applied for the complex financial instruments that are based on two price processes:

$S=\frac{1}{2} \cdot \int_{-\infty}^{+\infty} \int_{-\infty}^{+\infty}(\sqrt{f(x, y)}-\sqrt{g(x) \cdot h(y)})^{2} d x d y$

where $f(x, y)$ - joint probability density function of the bivariate random variable; $g(x)$ - probability density function of the random variable $\mathrm{x} ; \mathrm{h}(\mathrm{y})$ - probability density function of the random variable $\mathrm{y}$.

The positive value of $S$ testifies to a correlation between the random variables (financial variables) $\mathrm{x}$ and $\mathrm{y}$. The higher the value $S$, the stronger the correlation.

This measure is applicable for the two different variables' case in comparison with the Kullback-Leibler distance. The latter characterizes a distinction between two distributions on the same training set.

Nonlinear correlation between the price processes is provided by fundamental market laws, in particular those grasped by the Mundell-Fleming model [Fleming, 1962; Mundell, 1963], also known as the IS-LM-BoP model. As shown below, the structured product that accounts for the fundamental market laws is cheaper than conclusion of several deals - the components of the product. This complex financial instrument is beneficial to the market.

Table 3 presents the examples of the proposed structured products.

Table 3. The proposed structured products

\begin{tabular}{|c|c|c|c|}
\hline No & Product name & Short description of the product & $\begin{array}{l}\text { Financial market requirements } \\
\text { that are satisfied by the product }\end{array}$ \\
\hline 1 & 2 & 3 & 4 \\
\hline 1 & $\begin{array}{l}\text { The Barrier } \\
\text { Bermuda Foreign } \\
\text { Exchange EUR/ } \\
\text { USD INTEREST- } \\
\text { ing Swaption }\end{array}$ & $\begin{array}{l}\text { The product is an agreement between } \\
\text { the buyer and the seller that gives the } \\
\text { holder the right to buy (or sell) at expiry } \\
\text { T a difference between two underlying } \\
\text { assets at a specified strike value. The } \\
\text { first (variable x) is a ratio of EURIBOR } \\
3 \mathrm{M} \text { to EUR/USD currency quote. The } \\
\text { second (variable y) is LIBOR USD } 3 \mathrm{M} \text {. } \\
\text { An expiry T is defined by the underlying } \\
\text { assets motion with regard to a complex } \\
\text { structure of knock-in and knock-out } \\
\text { barriers }\end{array}$ & $\begin{array}{l}\text { - requirement of the market participants for } \\
\text { the lower cost analogues of the existing instru- } \\
\text { ments; } \\
\text { - requirement of the traders for the bundle } \\
\text { instrument that combines several multipar- } \\
\text { tite deals in the foreign exchange and money } \\
\text { markets. A long (or a short) position with } \\
\text { the structured product substitutes three open } \\
\text { positions with the standardized contracts: one } \\
\text { FX option, two interest rate swaptions (e.g. the } \\
\text { structured product may be beneficial to the } \\
\text { trader that has the liabilities linked to LIBOR } \\
\text { USD 3M, and the yield depended on EURI- } \\
\text { BOR 3M) }\end{array}$ \\
\hline 2 & $\begin{array}{l}\text { Structured Volatili- } \\
\text { ty Indices Strangle } \\
\text { Swaption with a } \\
\text { swap settlement at } \\
\text { expiry }\end{array}$ & $\begin{array}{l}\text { The product is an agreement between } \\
\text { the buyer and the seller that gives the } \\
\text { holder the right to buy (or sell) at expiry } \\
\text { T a difference between two underlying } \\
\text { assets at a specified strike value. The } \\
\text { first (variable x) is a market value of } \\
\text { the CBOE Volatility Index VIX. The } \\
\text { second (variable y) is a market value of } \\
\text { the EURO STOXX } 50 \text { Volatility Index } \\
\text { VSTOXX }\end{array}$ & $\begin{array}{l}\text { - requirement of the traders for the integration } \\
\text { of several frequently concluded multipartite } \\
\text { deals into one standardized contract. Payout } \\
\text { functions of the structured product are iden- } \\
\text { tical to the corresponding payout functions of } \\
\text { the long/short Strangle position that joins buy/ } \\
\text { sell of the call and put volatility indices options; } \\
\text { both options have the same expiry; } \\
\text { - requirement of the financial institutions for } \\
\text { an impetus to liquidity of a range of instru- } \\
\text { ments in the financial market (in particular, } \\
\text { VSTOXX options) }\end{array}$ \\
\hline
\end{tabular}


3

Structured Volatility Indices Risk reversal Swaption with a swap settlement at expiry, (Structured Volatility Collar when trader has open positions with underlying assets)
The product is an agreement between the buyer and the seller that gives the holder the right to buy (or sell) at expiry $\mathrm{T}$ an aggregate value (a sum) of two underlying assets at a specified strike value. The first (variable $\mathrm{x}$ ) is a market value of the CBOE Volatility Index VIX. The second (variable y) is a market value of the EURO STOXX 50 Volatility Index VSTOXX
- requirement of the traders for the integration of several frequently concluded multipartite deals into one standardized contract. Payout functions of the structured product are identical to the corresponding payout functions of the long/short Risk reversal position that joins buy/sell of the call and sell/buy of the put volatility indices options; both options have the same expiry;

- requirement of the financial institutions for an impetus to liquidity of a range of instruments in the financial market (in particular, VSTOXX options)

\section{Sources: author's development.}

We have estimated the fair values of the proposed products by applying a Black model modification based on Gaussian distribution and the proposed model based on non-Gaussian distribution.

Relating to the Structured six-month Volatility Indices Risk reversal call Swaption (the product No 3; entry: 20.11.2014, expiry: 20.05.2015, strike price: 44 percentage points). The Hellinger-Matusita-Bhattacharya distance S (13) equals $0,71$. This fact testifies a strong correlation between the financial variables $\mathrm{x}$ and $\mathrm{y}$ that characterize the dynamics of the volatility indices VIX and VSTOXX respectively. The non-Gaussian skewed joint probability density function w(x,y) that is the solution of the bivariate Prigogine equation (5) with given right parts of the dynamical system is following:

$w(x, y)=1-y+34,2 \cdot(x-1) \cdot y-376,0 \cdot\left(x^{2}-1\right) \cdot y-175,8 \cdot\left(x^{3}-1\right) \cdot y+461,5 \cdot\left(x^{4}-1\right) \cdot y$

The right parts of the equations of motion (6) describe a time evolution of the volatility indices VIX and VSTOXX:

$$
\begin{aligned}
& \frac{d x(t)}{d t}=E(x, y)=0,233 \cdot x-0,041 \cdot y+0,293 \cdot x \cdot\left(x^{2}+y^{2}\right)-0,183 \cdot y \cdot\left(x^{2}+y^{2}\right) \\
& \frac{d y(t)}{d t}=G(x, y)=0,041 \cdot x+0,233 \cdot y+0,183 \cdot x \cdot\left(x^{2}+y^{2}\right)+0,293 \cdot y \cdot\left(x^{2}+y^{2}\right)
\end{aligned}
$$

The first five basis functions $\gamma(\mathrm{x}, \mathrm{y})$ constructed on power moments of the probability density function $\mathrm{w}(\mathrm{x}, \mathrm{y})$ are following:

$$
\gamma(\mathrm{x}, \mathrm{y})=\left(\begin{array}{c}
1 \\
3,464 \mathrm{x} \\
-0,152 \mathrm{x}+0,234 \mathrm{y}-10,983 \mathrm{x}^{2}+0,339 \\
-0,06 \mathrm{x}+0,2 \mathrm{y}+4,584 \mathrm{x}^{2}+10,808 \mathrm{y}^{2}-0,075 \mathrm{xy}-1,77 \\
-1,26 \mathrm{x}+0,07 \mathrm{y}+0,6 \mathrm{x}^{2}+28,8 \mathrm{x}^{3}+0,153 \mathrm{y}^{2}-3,363 \mathrm{xy}-0,05 \\
0,227 \mathrm{x}-1,602 \mathrm{y}+58,85 \mathrm{x}^{2} \mathrm{y}-13,835 \mathrm{x}^{2}+4,871 \mathrm{x}^{3}-5,62 \mathrm{y}^{2}-2,113 \mathrm{xy}+1,153
\end{array}\right) .
$$

The payout function for the long position with a call swaption:

$\Phi_{\text {call }}^{S}(y, x)=\left\{\begin{array}{c}(y+x)-K_{\text {Scall }}, \text { if }(y+x)>K_{\text {Scall }} \\ 0, \text { if }(y+x) \leq K_{\text {Scall }} .\end{array}\right.$

Table 4 demonstrates the results of estimating the range of the proposed structured financial products. 
Table 4. The results of the proposed structured products' estimates (over a period of 2014-2015)

\begin{tabular}{|c|c|c|c|c|c|}
\hline Estimation method & $\begin{array}{l}\text { Financial } \\
\text { product }\end{array}$ & $\overline{\mathbf{F}}$ & Emp & $\Delta$ & $\boldsymbol{\sigma}$ \\
\hline \multirow{3}{*}{$\begin{array}{l}\text { Analytical product estimation by applying } \\
\text { bivariate non-Gaussian distributions (the } \\
\text { proposed model) }\end{array}$} & I & $7.3 \%\left(^{*}\right)$ & $7.8 \%$ & $0.5 \%$ & - \\
\hline & II & $10.52 \mathrm{pp}\left(^{* *}\right)$ & $11.22 \mathrm{pp}$ & $0.7 \mathrm{pp}$ & - \\
\hline & III & $3.26 \mathrm{pp}$ & $3.42 \mathrm{pp}$ & $0.16 \mathrm{pp}$ & - \\
\hline \multirow{3}{*}{$\begin{array}{l}\text { Analytical non-Gaussian product estimation } \\
\text { as a sum of theoretical prices of replicated } \\
\text { derivatives }\end{array}$} & I & $7.7 \%$ & $7.8 \%$ & $0.1 \%$ & 0.154 \\
\hline & II & $11.72 \mathrm{pp}$ & $11.22 \mathrm{pp}$ & $-0.5 \mathrm{pp}$ & 2.70 \\
\hline & III & $3.63 \mathrm{pp}$ & $3.42 \mathrm{pp}$ & $-0.21 p p$ & 0.38 \\
\hline \multirow{3}{*}{$\begin{array}{l}\text { Product estimation as a sum of theoretical } \\
\text { prices of replicated derivatives by applying a } \\
\text { Black-Scholes model modification }\end{array}$} & I & $8.1 \%$ & $7.8 \%$ & $-0.3 \%$ & 0.506 \\
\hline & II & $12.08 \mathrm{pp}$ & $11.22 \mathrm{pp}$ & $-0.86 \mathrm{pp}$ & 7.10 \\
\hline & III & $4.33 \mathrm{pp}$ & $3.42 \mathrm{pp}$ & $-0.91 p p$ & 1.49 \\
\hline
\end{tabular}

where I - The Barrier Bermuda Foreign Exchange EUR/USD INTERESTing Swaption, call; II - Structured Volatility Strangle, call; III - Structured Volatility Risk reversal, call; $\overline{\mathbf{F}}$ - mean value of the theoretical price of the structured product; Emp - mean value of a sum of empirical premia of the replicated derivatives; $\Delta$ - difference between Emp and $\overline{\mathbf{F}} ; \sigma$ - mean squared deviation of the theoretical structured product price (as a sum of theoretical prices of the replicated derivatives) from a sum of empirical premia of the replicated derivatives; $\left({ }^{*}\right) \%$ of Notional principal amount; $\left({ }^{* *}\right) \mathrm{pp}$ - percentage point.

Sources: author's development; [European Exchange; European Money Markets Institute (EURIBOR rates archive); Federal Reserve Bank of St. Louis Economic research (LIBOR rates archive); OANDA (exchange rates archive); STOXX Limited; The Bloomberg Professional Service (Bloomberg Terminal); The Chicago Board Options Exchange (CBOE); U.S. Department of the Treasury (Daily Treasury Yield Curve Rates); Yahoo! Finance] - empirical data.

Figure 1 presents the curves that describe a time evolution of the product III fair value $\mathrm{F}(\mathrm{x}, \mathrm{y}, \mathrm{t})$ estimated by applying: - the proposed model (Aut curve) based on the density function $\mathrm{w}(\mathrm{x}, \mathrm{y})$, basis functions $\gamma(\mathrm{x}, \mathrm{y})$, see the formula (3); - Black-Scholes model modification (Black curve) based on a net theoretical premium as a difference between the theoretical premia of the options that form a Risk reversal strategy (theoretical options prices are estimated by a standard Black-Scholes model for the univariate price processes).

Figure 1 also demonstrates the curve Emp that describes a time evolution of the difference between the empirical prices:

- six-month put volatility index VIX option (entry: 20.11.2014, expiry: 20.05.2015, strike: 25 percentage points) - Ticker VIX UO 05/20/15 P25 Index (sell put trader's position) [The Bloomberg Professional Service (Bloomberg Terminal); The Chicago Board Options Exchange (CBOE); Yahoo! Finance];

- eight-month call volatility index VSTOXX option (entry: 18.09.2014, expiry: 20.05.2015, strike: 19 percentage points); - Ticker V2X 05/20/15 C19 Index (buy call trader’s position) [European Exchange; STOXX Limited; The Bloomberg Professional Service (Bloomberg Terminal)].

The product's price in percentage points is on the axis of ordinates. 
Figure 1. The curves that describe a time evolution of Structured Volatility Risk reversal call Swaption price

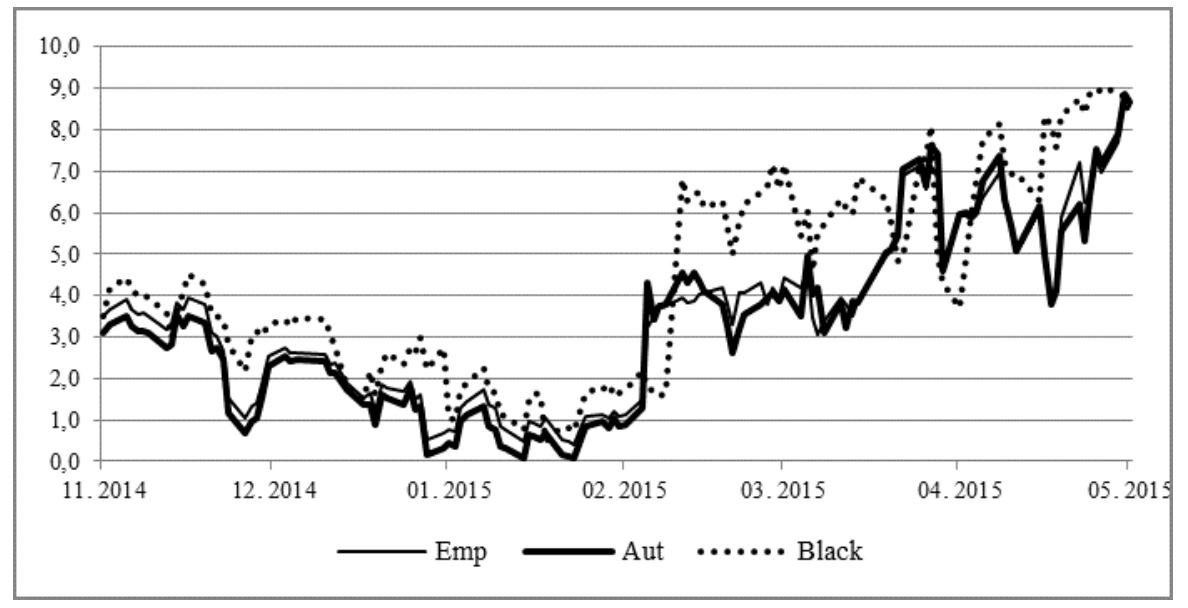

Sources: author's development; [European Exchange; STOXX Limited; The Bloomberg Professional Service (Bloomberg Terminal); The Chicago Board Options Exchange (CBOE); U.S. Department of the Treasury (Daily Treasury Yield Curve Rates); Yahoo! Finance] - empirical data.

Having considered the results of estimates of the proposed structured products based on two price processes, we are ready to summarize our findings as follows:

- the theoretical price of the structured product that is obtained by applying the bivariate non-Gaussian distribution based on the proposed model is lower than a sum of empirical prices of the replicated derivatives and is lower than a sum of theoretical prices of the components ${ }^{10}$. Moreover, a fair value of the structured product that is received as a sum of the theoretical prices of the replicated derivatives ${ }^{11}$ is higher than a sum of their empirical premia;

- mean squared deviation of a sum of the theoretical premia ${ }^{12}$ from the empirics is essentially lower than those obtained by the Black-Scholes model.

We have verified the Lyapunov stability of the proposed solution that is based on the bivariate non-Gaussian probability distributions of the underlying price processes of the structured products. Within the framework of each approach we have estimated the statistical reliability of all solution parameters.

\section{Work in progress}

The absence of a worldwide accepted model of an analytical estimation of the complex financial products is equal to the absence of the mechanism of their fair pricing. This situation suggests the higher risks and hence the overestimated premia.

The existing pricing techniques do not consider a correlation between underlying assets premia and the key characteristic of the financial market - a non-Gaussian stochastic behavior of price processes. As a solution to these fiascos we propose a crucially new model for an analytical estimation of a fair value of the structured financial products that is based on bivariate non-Gaussian skewed joint probability distributions of underlying assets price processes. The new approach considers a correlation between underlying assets and a non-Gaussian stochastic behavior of price processes.

We have reconstructed empirical premia of the structured products by applying various models that differ in characteristics of probability distributions of underlying price processes.

Having considered the results of reconstruction of a fair value of the complex financial instruments (both the existing and the proposed), we are ready to summarize our findings as follows:

- the proposed new theoretical approach provides the higher precision of estimate of the derivatives based on univariate stochastic price process (in comparison with the methods, currently worldwide accepted). Since these contracts are traded in the financial market, the efficiency of the application of the proposed model for the existing derivatives is verified;

- the estimate of the structured products that are not traded in the financial market is obtained. This estimate is compared with the replicated strategies that reproduce the structured contract by a set of traded instruments. The proposed approach provides the higher precision of estimating the replica in comparison with the Black-Scholes model;

\footnotetext{
${ }^{10}$ Each component is estimated on its own univariate non-Gaussian distribution.

11 Each derivative is estimated by the Black-Scholes model.

${ }_{12}$ The premia are received by the proposed non-Gaussian model.
} 
- the empirical performance of the proposed model proves a hypothesis about a non-Gaussian stochastic behavior of underlying price processes of the complex financial instruments;

- the proposed new theoretical approach reduces essentially the estimate of a fair value of the structured product with regard to the empirical premium, a sum of its underlying assets prices, and in comparison with the estimates received by other methods (Black-Scholes model modifications). This fact implies that the bundle instrument development that combines several deals with the correlated assets reduces essentially an overall structured derivatives price level.

Consequently, the development of an analytical estimation model based on a non-Gaussian distribution of the correlated underlying price processes is appealed to solve a problem of a fair pricing absence. It leads to reduction of premia level and provides an impetus to liquidity of the structured products market. These circumstances determine a demand of professional participants and financial institutions on the results of our research.

\section{References}

Baz J., Chacko G. (2004) Financial derivatives. pricing, applications and mathematics. Cambridge University Press. -338 p.

Björk T. (2009) Arbitrage theory in continuous time. Oxford Finance Series. - 560 p.

Black F., Scholes M. (1973) The Pricing of options and corporate liabilities. Journal of Political Economy, no. 81, pp. 637-654.

Bollerslev T., Todorov V. (2011) Estimation of jump tails. Econometrica, no. 79, pp. 1727-1783.

Bollerslev T., Todorov V. (2014) Time varying jump tails. Journal of Econometrics, no. 183, pp. 168-180.

Borland L. (2002a) A theory of non-gaussian option pricing. Quantitative Finance, no. 2, pp. 415-431.

Borland L. (2002b) Option pricing formulas based on a non-Gaussian stock price model. Physical Review Letters, vol. 89 , no. 9, pp. 1-12.

Cheuk T.H.F., Vorst T.C.F. (1996) Complex barrier options. Journal of Derivatives, no. 4, pp. 8-22.

Davydov D., Linetsky V. (2002) Structuring, pricing and hedging double-barrier step options. Journal of Computational Finance, winter, pp. 55-87.

Douady R. (1998) Closed-form formulas for exotic options and their lifetime distribution. International Journal of Theoretical and Applied Finance, no. 2, pp. 17-42.

Duda R.O., Hart P.E. (1973) Pattern classification and scene analysis. Wiley. $-512 \mathrm{p}$.

European Exchange. Available at: http://www. eurexchange.com/exchange-en/products/vol/vstoxx/ vstoxx--futures-and-options/VSTOXX-Futures/14566.

European Money Markets Institute (EURIBOR rates archive). Available at: http://www.euribor-ebf.eu/euribororg/euribor-rates.html.

Federal Reserve Bank of St. Louis Economic research (LIBOR rates archive). Available at: https://research. stlouisfed.org/fred2/release?rid=253.

Feller W. (1968) An introduction to probability theory and its applications. Wiley, 3ed edition. -527 p.
Feller W. (2015) Selected Papers I \& II. Springer Verlag International. - $1605 \mathrm{p}$.

Fleming J.M. (1962) Domestic financial policies under fixed and floating exchange rates. IMF Staff Papers, no. 9, pp. 369-379.

Fu M., Madan D., Wang T. (1997) Pricing Asian options: a comparison of analytical and Monte Carlo methods. Computational Finance, no 2, pp. 49-74.

Geman H., Yor M. (1993) Bessel Processes, Asian Options and Perpetuities. Mathematical Finance, no. 3, pp. 349-375.

Geman H., Yor M. (1996) Pricing and Hedging Double barrier Options: a Probabilistic Approach. Mathematical Finance, no. 6, pp. 365-378.

Granger C.W., Maasoumi E., Racine J. (2004) A Dependence metric for possibly nonlinear processes. Journal of time series analysis. Blackwell Publishing Ltd., vol. 25, no. 5, pp. 649-669.

Guckenheimer J., Holmes P. (2002) Nonlinear oscillations, dynamical systems, and bifurcations of vector fields. Springer. $-462 \mathrm{p}$.

Hui H.C. (1997) Time-dependent barrier option values. The Journal of Futures Markets, no. 17, pp. 667-688.

Hull J.C. (2014) Options, futures and other derivatives. Prentice Hall, 9th Edition. - 896 p.

Lasserre J.B., Prieto-Rumeau T., Zervos M. (2006) Pricing a class of exotic options via moments and SDP relaxations. Blackwell Publishing Inc., no. 3, pp. 469-494.

Linetsky V. (2004) Lookback Options and Diffusion Hitting Times: a spectral expansion approach. Finance and Stochastics, no. 8, pp. 373-398.

Linetsky V. (2004) Spectral expansions for Asian (Average Price) options. Operations Research, no 52, pp. 856-867.

Marsden J.E., McCracken M. (1976) The hopf bifurcation and its applications. Springer-Verlag. - 409 p.

Mathews J., Walker R.L. (1970) Mathematical methods of physics. W.A. Benjamin, 2nd edition. - 501 p.

Mattoo M. (1996) Structured derivatives: a handbook of structuring, Pricing \& Investor Applications. Financial Times Series. -320 p. 
Mundell R.A. (1963) Capital mobility and stabilization policy under fixed and flexible exchange rates. Canadian Journal of Economic and Political Science, vol. 29, no. 4, pp. $475-485$.

Nicolis G., Prigogine I. (1989) Exploring complexity: an introduction. St. Martin's Press. -328 p.

OANDA (exchange rates archive). Available at: http:// www.oanda.com/lang/ru/currency/historical-rates.

Pelsser A. (2000) Pricing double barrier options using analytical inversion of Laplace transforms. Finance and Stochastics, no. 4, pp. 95-104.

Risk magazine (Incisive Media). Available at: http://www. risk.net/structured-products.

S\&P Dow Jones Indices. Available at: http://eu.spindices. com/index-finder.

Structured Retail Products. Available at: http://www. structuredretailproducts.com.

STOXX Limited. Available at: https://www.stoxx.com/ index-details?symbol=V2TX, https://www.stoxx.com/ document/Bookmarks/CurrentComponents/SX5GT.pdf.

The Bloomberg Professional Service (Bloomberg Terminal). Available at: http://www.bloomberg.com/ professional.

The Chicago Board Options Exchange (CBOE)/ Available at: http://www.cboe.com/products/snp500.aspx, http:// www.cboe.com/micro/vix/part2.aspx, http://www.cboe. com/micro/vix-options-and-futures.aspx.

U.S. Department of the Treasury (Daily Treasury Yield Curve Rates). Available at: http://www.treasury.gov/ resource-center/data-chart-center/interest-rates/Pages/ TextView.aspx? data $=$ yield.

Voit J. (2005) The Statistical Mechanics of Financial Markets. Springer-Verlag. - 385 p.

Yahoo! Finance. Available at: http://finance.yahoo.com.

Wystup U. (2006) FX Options and Structured Products.

The Wiley Finance Series. - 343 p. 